\title{
Vertical Transmission of HIV-1 in the Metropolitan Area of Belo Horizonte, Brazil: 2006-2014
}

\section{Transmissão vertical do HIV-1 na área metropolitana de Belo Horizonte, Brasil: 2006-2014}

\author{
Victor Hugo Melo ${ }^{1}$ Marcelle Marie Martins Maia ${ }^{1}$ Mário Dias Correa Júnior ${ }^{1}$ Fabiana Maria Kakehasi ${ }^{1}$ \\ Flávia Gomes Faleiro Ferreira ${ }^{1}$ Beatriz Amélia Monteiro de Andrade ${ }^{2}$ Fernanda Sobral Scaramussa ${ }^{1}$ \\ Fernanda Alves Morais Ferreira ${ }^{1}$ Alfredo Augusto Messias ${ }^{1}$ Jorge Andrade Pinto ${ }^{1}$
}

${ }^{1}$ Faculdade de Medicina, Hospital das Clínicas, Universidade Federal de Minas Gerais, Belo Horizonte, MG, Brazil

Address for correspondence Victor Hugo Melo, MD, DSc, Faculdade de

2 Fundação Hospitalar do Estado de Minas Gerais, Belo Horizonte, Medicina/Hospital das Clínicas da Universidade Federal de Minas Gerais, MG, Brazil Belo Horizonte, MG, Brazil (e-mail: victormelo2401@gmail.com).

Rev Bras Ginecol Obstet 2018;40:59-65.

\section{Abstract \\ Keywords \\ - HIV infections \\ - infectious disease vertical transmission \\ - highly active antiretroviral therapy \\ - infectious pregnancy complications}

\section{Resumo}

Objective To revise HIV-1 vertical transmission (VT) rates in the metropolitan area of Belo Horizonte, Brazil, from January of 2006 to December of 2014.

Methods Descriptive study of a prospective cohort of HIV-1-infected pregnant women and their children, monitored by the Maternal and Child HIV/Aids Research Group of Research Group at Faculty of Medicine of Universidade Federal de Minas Gerais, Brazil.

Results The VT general rate was 1.9\% (13/673; confidence interval [CI] 95\%: 1.0-3.3). The extensive use of combined highly active antiretroviral therapy (HAART) (89.7\%; $583 / 650$ ) strongly impacted the reduction of VT during this period. Maternal viral load (VL) higher than 1,000 copies/mL showed significant association with VT (OR:6.6; Cl 95\%:1.3-33.3). Maternal breastfeeding was described in 10 cases in this cohort (1.5\%; Cl 95\%: 0.7-2.7), but it was not associated with VT.

Conclusion The present cohort data were coherent with the low VT rate described in other global populations, and it was considerably lower in comparison to the results of the same cohort during the period of 1998-2005, when the VT rate was $6.2 \%$. These data confirm the efficiency of the National Guidelines, and emphasize the importance of adopting the international recommended procedures for prevention of mother-tochild transmission (MTCT) of HIV.

Objetivo Rever as taxas de transmissão vertical (TV) do HIV-1 na área metropolitana de Belo Horizonte, Brasil, de janeiro de 2006 a dezembro de 2014.

Métodos Estudo descritivo de uma coorte prospectiva de gestantes infectadas pelo HIV-1 e seus filhos, monitorados pelo Grupo de Pesquisa em HIV/Aids Materno-Infantil, da Faculdade de Medicina da Universidade Federal de Minas Gerais, Brasil. received

August 30, 2017

accepted

November 8, 2017

published online

December 18, 2017
DOI https://doi.org/

10.1055/s-0037-1613689.

ISSN 0100-7203.
Copyright $@ 2018$ by Thieme Revinter

Publicações Ltda, Rio de Janeiro, Brazil
License terms

()(1) $\Theta \circledast$ 
Palavras-Chave

- infecções por HIV

- transmissão vertical de doença infecciosa

- terapia antirretroviral de alta atividade

- complicações infecciosas na gravidez
Resultados A taxa geral de TV foi de 1,9\% (13/673; intervalo de confiança [IC] 95\%: 1,0-3,3). O uso extensivo de terapia antirretroviral combinada (TARVc) $(89,7 \% ; 583$ / 650 ) impactou fortemente a redução de TV durante este período. Carga viral materna superior a 1.000 cópias/mL mostrou associação significante com TV (OR: 6,6; IC $95 \%: 1,3-33,3)$. A amamentação materna foi descrita em 10 casos nesta coorte $(1,5 \%$; IC 95\%: 0,7-2,7), mas não foi associada à TV.

Conclusão Os dados atuais da coorte foram coerentes com a baixa taxa de TV descrita em outras populações globais, e foi consideravelmente menor em comparação com os resultados da mesma coorte no período de 1998-2005, quando a taxa de TV foi de $6,2 \%$. Esses dados confirmam a eficiência das Diretrizes Nacionais, e enfatizam a importância de adotar os procedimentos internacionais recomendados para a prevenção da transmissão do HIV da mãe para o filho.

\section{Introduction}

It is estimated that, until June of 2015, in Brazil, there were 798,366 cases of persons infected with the human immunodeficiency virus (HIV). Among them, 8.4 for each 100 thousand inhabitants were children under 15 years old. Upon evaluating the exposition category among individuals below 13 years old, almost all cases had vertical transmission (VT) as the form of infection. ${ }^{1}$

In the period from January of 2000 to June of 2015, 92,210 cases of pregnant women with HIV were registered, and most of them resided in the Southeast region (40.5\%). In Belo Horizonte, the epidemiological results at the end of 2013 showed HIV detection in 1.9 of each 1,000 live births. ${ }^{1}$

From the start of the HIV/AIDS pandemic until modern days, effective interventions for reducing HIV VT were identified, such as: use of antiretroviral therapy (ART) during pregnancy, regardless of the maternal immunological state; elective cesarean section on some specific situations; and replacement of maternal breastfeeding for infant formula. ${ }^{2-9}$

In addition, recent studies showed that the early start of ART not only improved the life quality of HIV-infected pregnant women, ${ }^{10}$ but also reduced the risk of virus transmission. ${ }^{4,11} \mathrm{~A}$ viral load $(\mathrm{VL})$ reduction to undetectable levels as a consequence of using ART, associated with an adequate indication of mode of delivery and with no maternal breastfeeding, decreased the HIV mother-to-child transmission (MTCT) risk. This was evidenced by the reduction of VT rates from $25 \%$ to less than $1 \%{ }^{3,5,12-14}$ Therefore, throughout the years, these recommendations have been adopted by several countries, including Brazil, and also by the World Health Organization (WHO). ${ }^{15}$

Interventions such as those described substantially reduced the HIV VT risk and were incorporated into the national recommendations for the treatment of pregnant women with HIV. ${ }^{6}$ In Belo Horizonte, the broadening of access to the services of VT prevention resulted in an important decrease in new cases of neonatal infection, between the years 2006 and $2014{ }^{1}$

Thus, in the current scenario, it is relevant to describe the local epidemiology of HIV VT, the procedures that are being developed for the infection's prevention, and the effectivity of the currently proposed measurements for the reduction of the virus perinatal transmission. Therefore, the proposition of the present study is to assess the VT rate in a perinatal cohort of mothers from the metropolitan area of Belo Horizonte infected with the HIV-1, and identify the main risk factors for this transmission.

\section{Methods}

\section{Population and Study Design}

This is a prospective observational study performed at Hospital das Clínicas da Universidade Federal de Minas Gerais, and at a reference center on infectious and parasitic diseases, both in the state of Minas Gerais, Brazil, including HIV-1-infected pregnant women and their exposed newborns, both followed in the outpatient clinic, from January of 2006 to December of 2014.

The clinical and laboratory data were collected via standardized forms, including maternal data about the HIV-1 infection, the pregnancy and labor, the ART during the pregnancy, and the disease's classification, according to the Centers for Disease Control and Prevention (CDC). ${ }^{16}$ The results of lymphocytes T CD4 counting and maternal VL performed within 3 months before and/or after labor were also collected for analysis. Children were monthly evaluated during the first 6 months of life and, then, every 3 months, until the definition of their infectious status, with the compilation of the clinical and laboratory data of these visits.

The modes of delivery were categorized as elective C-section, intrapartum C-section, or vaginal delivery. The antiretroviral schemes were described as: zidovudine as monotherapy (ZDV); double therapy with two nucleoside analog reverse-transcriptase inhibitors (NARTIs); and combined highly active antiretroviral therapy (HAART), with two NARTIs plus a protease inhibitor or a non-nucleoside reverse-transcriptase inhibitor (NNRTI); or no therapy in any stage of pregnancy. The time of rupture of membranes was considered prolonged if it occurred 4 hours or more before the birth. Children were classified as low birth weight if they weighed less than $2,500 \mathrm{~g}$, and as premature if the birth occurred before 37 weeks of gestational age, evaluated by the physical exam upon birth or by the estimated gestational age. ${ }^{17}$ The HIV-1 infection was defined in children presenting: a) plasmatic VL higher than 5,000 copies $/ \mathrm{mL}$ in 
two different samples collected after four weeks of life; $b$ ) any class $C$ diagnosis according to the $C D C$ pediatric rating of HIV-1/AIDS; ${ }^{16}$ c) persistently positive HIV-1 antibodies research (enzyme immunoassay tests and Western blot) after 18 months of age.

The perinatal cohort, which started in 1997 and is ongoing, was previously approved by the Research Ethics Committee of the institution (ETIC 008/97). More details regarding the methodology and definitions of the cohort can be found in the previous publication. ${ }^{18}$ As with any prospective cohort, and following the national guidelines for HIV treatment during pregnancy, we observed a significant indication of a more complex antiretroviral regimen than in the previous study, which had included Zidovudine monotherapy. ${ }^{18}$

\section{Statistical Analysis}

The database was generated in EpiData, version 2.1 (EpiData Association, Odense, Denmark), and the analyses were performed using the SPSS software, version 17.0 (SPSS Inc. Chicago,IL, USA). The relations between maternal factors and the children's infectious status were initially assessed via univariate analysis, chi-squared test, Fisher exact test, chi-squared test for tendency, Mann-Whitney test and odds ratio (OR) estimate. A confidence interval (CI) of $95 \%$ was used. The multivariate analysis was performed using the logistic regression model in the following sequence: preliminary selection of the univariate analysis' variables, with inclusion in the multivariate model of those with $p<0.25$ and a few variables that, although they did present values of $p<0.25$, are described in the literature as associated to VT risk. The modeling was performed via construction of complete models with all the variables selected for the analysis and the successive disposal of the variables that did not change, in a significant way, the related OR and CIs. For the construction of the final model, the level of significance considered was of 0.05 . The evaluation of the models was performed using the likelihood ratio test.

\section{Results}

During the period from January of 2006 to December of 2014, 690 mother-child pairs were evaluated. However, the present study was performed with 673 pairs, because data of 17 pairs $(2.5 \%)$ were excluded due to the non-definition of the child's infectious status. Mother-to-child-transmission of HIV-1 was found in 13 children (13/673 - 1.9\%; CI 95\%: 1.0-3.3) in this period. As shown in - Fig. 1, the number of infectious cases each year was 3 in 2006, 4 in 2007, 2 in 2008, 1 case 2010, 2 in 2013 and 1 in 2014, with relative reduction of $21.7 \%$ of VT rate during the study period.

According to the self-declared racial origin, 268 (39.8\%) of the interviewed mothers considered themselves as African descendent, 442 (65.7\%) had a stable marital relationship and $322(47.9 \%)$ had less than 8 years of formal education. Information regarding how women in the study acquired HIV-1 was available in 501 (74.5\%), and in $89.7 \%$ of them, the most frequent way of infection was the contact with an HIV-infected

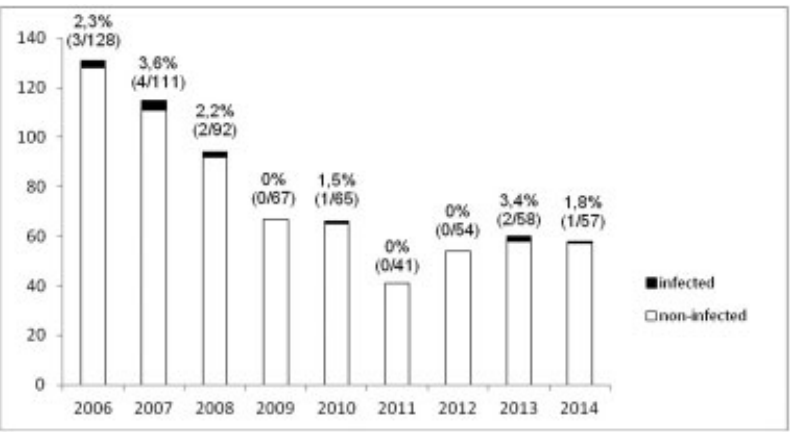

Fig. 1 Trends of HIV vertical transmission rate among HIV-1-infected women.

partner. The majority of the pregnant women was asymptomatic or had mild symptomatology (CDC93 Class A). Information on the timing of rupture of the membranes was available in only $236(35.0 \%)$ cases, and there was no association with a higher risk of HIV VT. Maternal complications during pregnancy, such as urinary tract infection and/or vulvovaginitis, were also not associated with VT $(p=0.06)$, despite being in the limit of statistical significance.

Some maternal characteristics are presented in - Table 1. There was no difference between the age of mothers with infected and non-infected children $(p=0.42)$. Fifty-one (10.2\%) mothers affirmed being illicit drug users and the use was almost significantly associated with a higher risk of VT $(p=0.05$; $\mathrm{OR}=6.0$; Cl 95\%: 0.9-36.9). A maternal VL higher than 1,000 copies/mL was significantly associated with a higher risk of VT (OR: 6.6; CI 95\%: 1.3-33.3), and a tendency of association with maternal immunosuppression may be observed. There was no significant difference between the infected and non-infected children regarding median weight at birth $(2,680 \mathrm{~g}$ versus 2,855 g respectively; $p=0.23$ ), low weight at birth $(38.5 \%$ versus $23.2 \%$, respectively, $p=0.21$ ), or prematurity $(33.3 \%$ versus $17.6 \% ; p=0.17$ ). Maternal breastfeeding was reported by only 10 mothers $(1.5 \%)$ in this cohort and there was no significant difference in HIV-1 VT (OR: 7.0; CI 95\%: 0.8-60.7). There were three cases in 2006, four in 2007, and one case in 2008, 2009 and 2010, each. The most common neonatal complications were precocious jaundice and respiratory disorders. The occurrence of any neonatal complications was more frequently found in HIV-1-infected children, showing a significant association with HIV-1 VT (OR: 4.5; CI 95\%:1.3-15.1).

The mode of delivery varied along the studied period, with the tendency of cesarean rates being higher than the vaginal delivery rates, mainly in 2011 and 2013 (-Fig. 2). Vaginal delivery route was not associated with a higher risk of HIV transmission (OR: 0.2; CI 95\%: 0.1-1.6).

A gradual increase of ART use during pregnancy was observed during the years of study, varying from $80.2 \%$ of the pregnant women in 2006 to $\sim 100 \%$, from 2010 to 2014 . Prescription of highly active antiretroviral therapy (HAART) was also observed, going from $74.5 \%$, in 2006 , to $100 \%$, in $2014(p=0.08)$ (-Fig. 3).

The variables for multivariate analysis were selected from - Table 1, adopting as selection criterion the value of 
Table 1 Characteristics of HIV-infected woman and their infants in the study population, according to HIV-1 vertical transmission $(n=673)$

\begin{tabular}{|c|c|c|c|c|}
\hline Characteristics & $\begin{array}{l}\text { Vertical Transmission } \\
\text { Yes }(n=13)(\%)\end{array}$ & $\begin{array}{l}\text { Vertical Transmission } \\
\text { No }(n=660)(\%)\end{array}$ & $p$ & OR (CI 95\%) \\
\hline \multicolumn{5}{|l|}{ Maternal } \\
\hline Average age (years) & 30.1 & 30 & $0.42^{a}$ & - \\
\hline \multicolumn{5}{|l|}{ Illicit drugs use ${ }^{b}$} \\
\hline Yes & 2 & 48 & 0.05 & $6.0(0.9-36.9)$ \\
\hline \multicolumn{5}{|l|}{ Antiretroviral regimen ${ }^{b}$} \\
\hline HAART & $9 / 12(75)$ & $553 / 617(89.6)$ & & $1^{c}$ \\
\hline Dual therapy & 0 & $5 / 617(0.8)$ & & - \\
\hline Monotherapy (ZDV) & 0 & $14 / 617(2.3)$ & & - \\
\hline None & $3 / 12(25)$ & $45 / 617(7.3)$ & 0.04 & $4.1(1.1-15.8)$ \\
\hline \multicolumn{5}{|l|}{ Mode of delivery ${ }^{b}$} \\
\hline Elective cesarean & $8 / 12(66.7)$ & $287 / 653(44)$ & & $1^{c}$ \\
\hline Intrapartum cesarean & $1 / 12(8.3)$ & $97 / 653(15)$ & 0.29 & $0.3(0.04-2.7)$ \\
\hline Vaginal & $3 / 12(25)$ & $269 / 653(41)$ & 0.20 & $0.2(0.1-1.6)$ \\
\hline Median Lymphocytes T CD4+ (cells/mm³) & 281 & 525 & & \\
\hline IQR (25-75\%) & $(27-603.5)$ & $(364.8-728.8)$ & $0.06^{a}$ & - \\
\hline Viral load median $(\log )$ & 4.2 & 0.0 & & \\
\hline IQR (25-75\%) & $(1.4-4.8)$ & $(0-2.3)$ & $0.00^{a}$ & - \\
\hline Viral load $>1,000$ copies $/ \mathrm{mL}$ & $3 / 6(50.0)$ & $63 / 477(13.2)$ & 0.02 & $6.6(1.3-33.3)$ \\
\hline \multicolumn{5}{|l|}{ Newborns } \\
\hline Weight at birth (grams) & 2,680 & 2,855 & $0.23^{a}$ & - \\
\hline IQR (25-75\%) & $(2,120-3,030)$ & $(2,560-3,175)$ & & \\
\hline Low birth weight ${ }^{b}$ & $5 / 13(38.5)$ & $151 / 652(23.2)$ & 0.21 & $2.1^{c}(0.7-6.2)$ \\
\hline Prematurity ${ }^{b}$ & $4 / 12(33.3)$ & $109 / 621(17.6)$ & 0.17 & $2.4^{c}(0.7-7.9)$ \\
\hline Maternal breastfeeding ${ }^{b}$ & $1 / 11(9.1)$ & $9 / 640(1.4)$ & 0.08 & $7.0^{c}(0.8-60.7)$ \\
\hline Neonatal complications ${ }^{b}$ & $8 / 12(66.7)$ & $197 / 639(30.8)$ & 0.02 & $4.5^{c}(1.3-15.1)$ \\
\hline
\end{tabular}

Abbreviation: $\mathrm{Cl}$, confidence interval; HAART, highly active antiretroviral therapy; HIV, human immunodeficiency virus; IQR, interquartile; OR, odds ratio; ZDV, zidovudine.

${ }^{\mathrm{a}}$ Mann Witney Test; ${ }^{\mathrm{b}}$ Chi-squared test; ${ }^{\mathrm{c}}$ Odds ratio (Cl 95\%).

Note: It was not possible to obtain all the information for some of the variables.

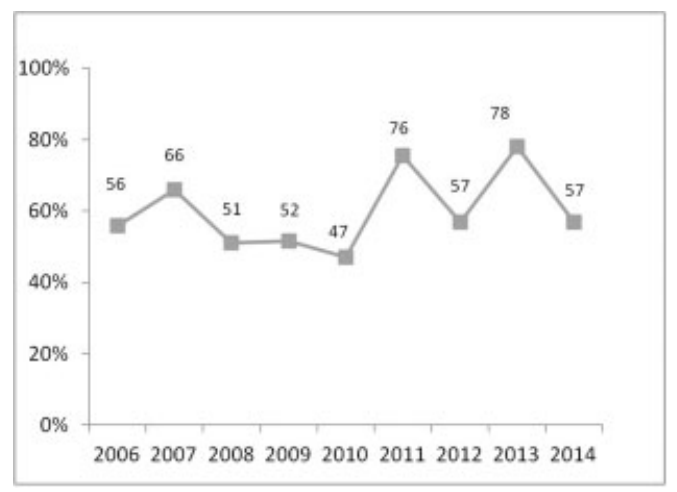

Fig. 2 Elective and/or intrapartum cesarean rates of HIV-1-infected pregnant women enrolled in a prospective cohort of patients from 2006 to 2014.

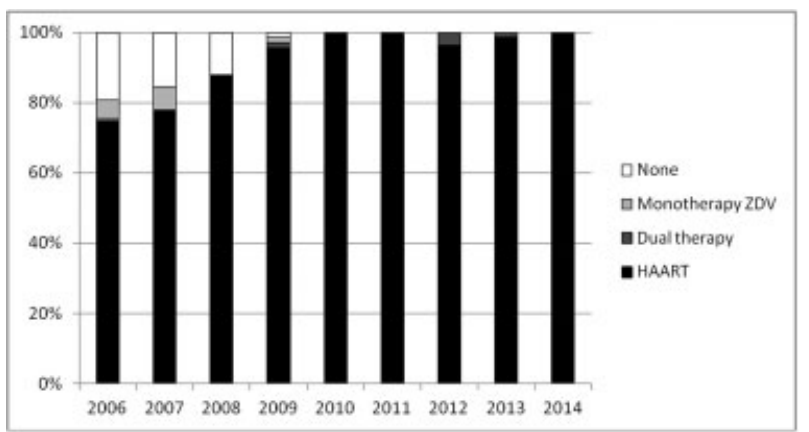

Fig. 3 Distinct antiretroviral therapy regimens used by HIV-infected pregnant women in a prospective cohort of patients from 2006 to 2014. Abbreviations: HAART, highly active antiretroviral therapy; ZDV, zidovudine. 
$p<0.25$, and also including those that, despite not presenting this $p$ value, are described in the literature as associated with VT. The following variables were selected: maternal VL higher than 1,000 copies/mL; maternal use of ART; method of delivery; low birth weight: prematurity; neonatal complications; and maternal breastfeeding. Maternal VL $>1,000$ copies/mL was the single risk factor that remained associated with VT in the logistic regression's final model (OR: 6.6; CI 95\%: $1.3-33.3 ; p=0.02$ ).

\section{Discussion}

There are evidences that in the absence of interventions during prenatal care and delivery of pregnant women infected by HIV, VT rates from 15 to $45 \%$ are observed, and with effective interventions, there is a reduction to rates as low as $5 \%{ }^{19}$ These interventions are already well consolidated in the literature, and include: universal tracking of pregnant women; ART use during prenatal care and delivery, with consequent VL reduction; definition of mode of delivery according to the VL near the time of delivery; administration of ART to the newborn; and replacement of maternal breastfeeding with infant formula. $2,5,7-9,20$

Significant temporal reduction is observed in the HIV VT rate of the present study (1.9\%), when compared with the period from 1998 to 2005 , for which it was $6.2 \%(p<0.05) .^{18}$ Concomitantly, we could observe the progressive increase of ART use during pregnancy, with a prescription rate of $80.2 \%$ in 2006 and reaching practically all women in 2014, associated to a more complex regimen.

National studies have observed a similar decrease of HIV MTCT. A study performed in Rio Grande do Sul, involving 389 pairs of mothers and children, from 2002 to 2005, showed ART use in $86.6 \%$ of the pregnant women and a VT rate of $2.8 \% .{ }^{21}$ In another study, that involved 353 pregnant women and their newborns- 102 pairs of mothers and children between 1998 and 2004, and 251 between 2005 and 2011-a significant reduction in VT rates was observed, from $11.8 \%$ to $3.2 \%$, respectively $(p<0.001)$. According to these authors, the increase of HAART use during pregnancy, the reduction of the maternal VL and an interval lower than 4 hours between the rupture of the membranes and birth were the factors that were associated with VT reduction. ${ }^{22}$

Barral et al, ${ }^{23}$ analyzing the results of 262 pairs of mothers and children from 2003 to 2007 , found a VT rate of $3.8 \%$. Two risk factors significantly contributed for maternal-fetal transmission, according to these authors: no use of HAART by pregnant women, and non-adherence to prenatal care at referral service. Another study, performed in Alagoas, evaluating the results of 76 pairs of mothers and children, showed that $19.0 \%$ of the pregnant women did not perform the prophylaxis with ART during the pregnancy, and $22.4 \%$ in the peripartum period, resulting in a VT rate of $6.6 \%$. According to these authors, the lost opportunities for VT prevention were: late start of prenatal care, with all its consequences; late start of ART use in the newborns; and maternal breastfeeding. ${ }^{24}$ The present study evidences significant reduction of VT observed at a reference center for HIV-infected preg- nant women, over time, especially for the increase in the implementation of interventions that, in concordance with other national studies, seem to more deeply impact the reduction of the HIV risk of VT.

In 1999, the WITS (Women and Infants Transmission Study Group) confirmed the association between near childbirth VL higher than 1,000 copies/mL and elevated rates of VT. ${ }^{25}$ Following this landmark study, a national publication, analyzing data of 262 pairs of mothers and children, confirmed the association of maternal near childbirth VL higher than 1,000 copies/mL and the infection in the newborn, presenting similar results to those of the present study (OR-4.98; CI 95\%:1.3218.7). ${ }^{23}$ Townsend et al, ${ }^{26}$ evaluating MTCT rates in 11,515 newborns of HIV-positive pregnant women in the UK, between 2000 and 2011, noted a significant decline from 2000/2001 (2.1\%) to $2010 / 2011(0.46 \%)(p<0.01)$. This reduction was attributed to a series of combined factors, especially to early diagnosis in pregnancy and subsequent immediate start of ART. The VT risk was higher among pregnant women with VL $>50$ copies/mL, compared with those with $\mathrm{VL}<50$ copies $/ \mathrm{mL}$ $(p<0.001)$. The multi-central perinatal cohort for Latin America and Caribbean countries, involving 711 pairs of pregnant women and newborns recruited between 2002 and 2009, presented a VT rate of $1.4 \%$ (CI 95\%:0.7-2.6) and showed that elevated VL during pregnancy was one of the main factors associated with HIV transmission. ${ }^{27}$

On the other hand, a meta-analysis published in 1999 showed a strong reduction of HIV VT associated with elective cesarean section in patients with VL above 1,000 copies $/ \mathrm{mL}$, or unknown, close to birth. ${ }^{28}$ Therefore, several countries started adopting the VL screening around the 34th week of pregnancy to elect the mode of delivery. Currently, for pregnant women undergoing ART, and with VL suppression (or undetectable VL), vaginal delivery is recommended, except if there is any factor to contraindicate the vaginal delivery. ${ }^{2,6}$ In our study, maternal VL higher than 1,000 copies/mL had significant association with VT (OR-6.6; CI 95\%: 1.3-33.3), corroborating data from the literature. A high transmission rate was verified in 2013 (3.4\%), in spite of ART prescription for almost all pregnant women, in association with a high caesarean rate (78.0\%), showing a heroic attempt of additional intervention for HIV VT.

A floating standard was observed in the mode of delivery for the pregnant women included in the present study, with a reduction of cesarean rates, favoring vaginal delivery, from 2008 to 2010. However, surgical procedure rates increased again, mainly in 2011 and in 2013, for the most diverse reasons: $\mathrm{VL}>1,000$ copies/mL, or unknown viremia close to birth; iterativity; rupture of membranes; increase in intrapartum cesarean indications; pelvic presentation; fetal suffering; cephalopelvic disproportion. It is important to highlight that the number of new HIV-infected pregnant women in our service decreased to approximately half of the annual population in the follow-up. This may justify the more frequent indication of cesarean section as the main intervention in a population with a previous $\mathrm{C}$-section.

The elective caesarean reduces the VT rates in pregnant women not undergoing ART, ${ }^{28}$ or among those who use zidovudine (ZDV) in monotherapy. ${ }^{29}$ However, even in the 
age of combined ART, the mode of delivery method is still under discussion. An European multicenter study showed that the elective cesarean reduces HIV VT, when compared with vaginal delivery or emergency cesarean, in patients with VL between 50 and 400 copies/mL (OR: 0.20; CI 95\%: 0.05-0.65). The difference was not significant for patients with VL below 50 copies $/ \mathrm{mL} .{ }^{30}$ Another study performed in the UK showed that the VT rates were higher in patients with vaginal delivery, even after adjustment regarding the use of ART (OR: 4.16; CI 95\%: 1.66-10.41). ${ }^{12}$ Such findings motivated some authors to recommend elective cesarean for patients with VL between 50 and 400 copies/mL, against most of the international protocols, which recommend elective cesarean only for patients with VL above 1,000 copies $/ \mathrm{mL}^{31}$ Additional analysis over time will be required to indicate the protective effect of the surgical method in our population.

Regarding intrapartum ZDV administration, some authors have shown that around 77 to $92.8 \%$ of women received the medicine during the period of the study. Its non-administration may be explained by the lack of time- due to the late arriving of women in the maternity at the last stage of delivery - and also due to the non-availability of ZDV in the hospital, or because the HIV testing was done after childbirth. ${ }^{20}$ In our study, there was a peripartum/intrapartum ZDV use of $85.3 \%$ for attack dose, and $71.8 \%$ for maintenance dose, for similar reasons to those mentioned in the literature.

The information about the time of membranes rupture was available for only $35 \%$ of the population in our study, but there was no case of VT associated with this occurrence. Therefore, a more conclusive evaluation of the non-registered information cannot be made. A meta-analysis involving 4,721 HIV-infected pregnant women who did not breastfeed, and whose time interval between the rupture of membranes and childbirth was lower than 24 hours, showed that the VT risk increased 2\% (OR1.02: CI 95\%:1.01-1.04) for each hour between the time of rupture and the birth. ${ }^{32}$ These findings reinforced the recommendations of international protocols for maintaining the integrity of the membranes during labor and, in the case of rupture, it is proposed that the labor should occur within a maximum of 4 hours after this event, to avoid HIV VT. However, recent studies have challenged these results. Cotter et $\mathrm{al}^{33}{ }^{33}$ in a cohort involving 707 HIV-infected pregnant women using ART, and with 4 or more hours of rupture of membranes during labor, did not find higher VT rates when the antepartum VL was lower than 1,000 copies $/ \mathrm{mL}$. Similar results were found by Peters et al, ${ }^{34}$ in a cohort of 2,116 pregnant women and their newborns: The VT rate between women with term pregnancy and antepartum VL below 50 copies $/ \mathrm{mL}$ was of $0.14 \%$ for those with time of rupture of membranes above 4 hours, and $0.12 \%$ for women with less than 4 hours, without statistical significance (OR-1.14; CI 95\%:0.07-18.27).

Maternal breastfeeding is an additional transmission risk, once that the VT rate in the first weeks of life could reach 8.9 infections/100 children-year, among these neonates. However, for concomitant maternal treatment with ART during the breastfeeding period, the VT rate varies from 1 to $5 \%$, regardless of maternal VL. ${ }^{15}$ Therefore, breastfeeding is proscribed in HIV-infected mothers. It could be observed that breastfeeding was practically abolished in our cohort, occurring only on $1.5 \%$ of all cases, which is a significant reduction when compared with the previous study of $1998-2005$, when it was of $6.1 \%$ $(p<0.001) .^{18}$ In the current study, among mothers who breastfed, $80 \%$ had their children in hospitals other than the reference services, and only one infected newborn may be associated with maternal breastfeeding, in 2008. This patient did not show up for the follow-up in our referral service, suggesting a lost counseling opportunity. On the other hand, sociocultural and economic factors may also be responsible for the decision to breastfeed. A study performed in the northeast region of Brazil showed that children in this region are the most likely to be breastfed. At the same time, familiar and social expectations expose HIV-infected mothers to embarrassing situations and create different reasons to breastfeed. ${ }^{35}$

The results of the present cohort were coherent with the low HIV VT rates in the period, confirming the effectivity of the Ministry of Health's Guidelines, ${ }^{6}$ which follows the international protocols, and emphasize the importance of the interventions pointed out to prevent the maternal-fetal transmission of HIV. Finally, practically all patients were using ART, and an important reduction in VT rates was observed in the same period, which confirmed the need of ART for all HIV-infected pregnant women, regardless of the clinical and immunological criteria. It is also important to highlight that ART should not be discontinued after childbirth.

\section{Conclusion}

We conclude that, using the internationally recommended procedures for HIV VT prophylaxis adopted by the Brazilian Ministry of Health, the number of infected children can be effectively reduced. This study may also serve as a model to other reference centers in the monitoring of pregnant women with HIV, and it reinforces the impact of the implementation of these procedures on VT reduction over the years.

\section{Contributors}

Melo V. H., Maia M. M. M., Correa Júnior M. D., Kakehasi F. M., Ferreira F. G. F., Andrade B. A. M., Scaramussa F. S., Ferreira F. A. M., Messias A. A. and Pinto J. A. declared to have contributed with the conception of the study, collection, and tabulation, critically reviewing intellectual, drafting of the manuscript and final approval of the version to be published.

\section{Conflicts to Interest}

The authors do not have any conflict of interest.

\section{References}

1 Ministry of Health. Secretariat of Health Surveillance. STD Department, Aids and Viral Hepatitis. Epidemiological Bulletin HIV/AIDS 2015. http://www.aids.gov.br/pt-br/pub/2015/boletim-epidemiologico-hivaids-2015. Accessed February 15, 2016

2 Panel on Treatment of HIV-Infected Pregnant Women and Prevention of Perinatal Transmission. Recommendations for Use of Antiretroviral Drugs in Pregnant HIV-1-Infected Women for Maternal Health and Interventions to Reduce Perinatal HIV Transmission in the United States. Rockville, MD: Department of Health \& 
Human Services/AIDS Research Advisory Council (OARAC); 2015. https://aidsinfo.nih.gov/contentfiles/lvguidelines/Perinatal GL. pdf. Accessed February 15, 2016

3 Money D, Tulloch K, Boucoiran I, Caddy S; INFECTIOUS DISEASES COMMITTEE; SPECIAL CONTRIBUTORS. Guidelines for the care of pregnant women living with HIV and interventions to reduce perinatal transmission: executive summary. J Obstet Gynaecol Can 2014;36(08):721-734. Doi: 10.1016/S1701-2163(15)30515-6

4 Hughes B, Cu-Uvin S. Patient Information: HIVand Pregnancy (Beyond the Basics). Dec 2015. http://www.uptodate.com/contents/hiv-andpregnancy-beyond-the-basic. Accessed February 15, 2016

5 Anglemyer A, Rutherford GW, Horvath T, Baggaley RC, Egger M, Siegfried N. Antiretroviral therapy for prevention of HIV transmission in HIV-discordant couples. Cochrane Database Syst Rev 2013;(04):CD009153. Doi: 10.1002/14651858.CD009153.pub3

6 Ministry of Health. Secretariat of Health Surveillance. STD Department, Aids and Viral Hepatitis. [Clinic Protocols and Therapeutic Guidelines for the HIV Vertical Transmission Prevention, Syphilis and Viral Hepatitis]. Brasília, DF: Ministry of Health; 2015. http://www.aids.gov.br/pt-br/pub/2015/protocolo-clinico-e-diretrizes-terapeuticas-para-prevencao-da-transmissao-verticalde-hiv. Accessed February 15, 2016

7 Australian Government. The Department of Health. Clinical Practice Guidelines Antenatal Care. Module I: HIV. 2013. http://www. health.gov.au/internet/publications/publishing.nsf/Content/clinical-practice-guidelines-ac-mod1 $\sim$ part-b $\sim$ maternal-health-scre ening hiv. Accessed February 26, 2016

8 Palasanthiran P, Starr M, Jones C, Giles M. Management of Perinatal Infections. Sidney: Australasian Society for Infectious Diseases; 2014. https://www.asid.net.au/documents/item/368. Accessed February 26, 2016

9 Bitnun A, Brophy J, Samson L, et al. Prevention of vertical HIV transmission and management of the HIV-exposed infant in Canada in 2014. Can J Infect Dis Med Microbiol 2014;25(02):75-77

10 de Ruiter A, Taylor GP, Clayden P, et al; British HIV Association. British HIV Association guidelines for the management of HIV infection in pregnant women 2012 (2014 interim review). HIV Med 2014;15(Suppl 4):1-77. Doi: 10.1111/hiv.12185

11 Lundgren JD, Babiker AG, Gordin F, et al; INSIGHT START Study Group. Initiation of antiretroviral therapy in early asymptomatic HIV infection. N Engl J Med 2015;373(09):795-807. Doi: 10.1056/ NEJMoa1506816

12 Cohen MS, Chen YQ McCauley M, et al; HPTN 052 Study Team. Prevention of HIV-1 infection with early antiretroviral therapy. N Engl J Med 2011;365(06):493-505. Doi: 10.1056/NEJMoa1105243

13 Townsend CL, Cortina-Borja M, Peckham CS, de Ruiter A, Lyall H, Tookey PA. Low rates of mother-to-child transmission of HIV following effective pregnancy interventions in the United Kingdom and Ireland, 2000-2006. AIDS 2008;22(08):973-981. Doi: 10.1097/QAD.0b013e3282f9b67a

14 Warszawski J, Tubiana R, Le Chenadec J, et al; ANRS French Perinatal Cohort. Mother-to-child HIV transmission despite antiretroviral therapy in the ANRS French Perinatal Cohort. AIDS 2008;22(02):289-299. Doi: 10.1097/QAD.0b013e3282f3d63c

15 World Health Organization. Consolidated Guidelines on the Use of Antiretroviral Drugs for Treating and Preventing HIV Infection: Recommendations for a Public Health Approach. Geneva: WHO; Jun 2013. http://apps.who.int/iris/bitstream/10665/85321/1/ 978924 1505727_eng.pdf. Accessed February 1, 2016

16 Centers for Disease Control and Prevention. 1994 Revised classification system for human immunodeficiency virus (HIV) infection in children under 13 years' age. MMWR Morb Mortal Wkly Rep 1994;43:1-10

17 Capurro H, Konichezky S, Fonseca D, Caldeyro-Barcia R. A simplified method for diagnosis of gestational age in the newborn infant. J Pediatr 1978;93(01):120-122

18 Kakehasi FM, Pinto JA, Romanelli RMC, et al. Determinants and trends in perinatal human immunodeficiency virus type 1 (HIV-
1) transmission in the metropolitan area of Belo Horizonte, Brazil: 1998 - 2005. Mem Inst Oswaldo Cruz 2008;103(04):351-357. Doi: 10.1590/S0074-02762008000400007

19 World Health Organization. Mother-to-Child Transmission of HIV. Geneva: WHO; 2016. http://www.who.int/hiv/topics/mtct/en/. Accessed February 15, 2016

20 Mofenson LM. Prevention in neglected subpopulations: prevention of mother-to-child transmission of HIV infection. Clin Infect Dis 2010;50(Suppl 3):S130-S148. Doi: 10.1086/651484

21 Torres SR, Luz AMH. [HIV+ pregnant woman and exposed children: epidemiological study on compulsory notification]. Rev Gaúcha Enferm 2007;28(04):505-511

22 Rosa MC, Lobato RC, Gonçalves CV, et al. Evaluation of factors associated with vertical HIV-1 transmission. J Pediatr (Rio J) 2015; 91(06):523-528. Doi: 10.1016/j.jped.2014.12.005

23 Barral MFM, de Oliveira GR, Lobato RC, Mendoza-Sassi RA, Martínez AMP, Gonçalves CV. Risk factors of HIV-1 vertical transmission (VT) and the influence of antiretroviral therapy (ART) in pregnancy outcome. Rev Inst Med Trop São Paulo 2014;56(02):133-138. Doi: 10.1590/S0036-46652014000200008

24 Rodrigues STC, Vaz MJR, Barros SMO. Vertical transmission of HIV in the population treated at a reference center. Acta Paul Enferm 2013;26:158-164. Doi: 10.1590/S0103-21002013000200009

25 Garcia PM, Kalish LA, Pitt J, et al; Women and Infants Transmission Study Group. Maternal levels of plasma human immunodeficiency virus type 1 RNA and the risk of perinatal transmission. N Engl J Med 1999;341(06):394-402. Doi: 10.1056/NEJM199908053410602

26 Townsend CL, Byrne L, Cortina-Borja M, et al. Earlier initiation of ART and further decline in mother-to-child HIV transmission rates, 2000-2011. AIDS 2014;28(07):1049-1057. Doi: 10.1097| QAD.0000000000000212

27 Read JS, Cohen RA, Hance LF, et al; NISDI Perinatal/LILAC Study Group. Missed opportunities for prevention of mother-to-child transmission of HIV-1 in the NISDI Perinatal and LILAC cohorts. Int J Gynaecol Obstet 2012;119(01):70-75. Doi: 10.1016/j.ijgo.2012.05.026

28 Andiman W, Bryson Y, de Martino M, et al; International Perinatal HIV Group. The mode of delivery and the risk of vertical transmission of human immunodeficiency virus type 1-a meta-analysis of 15 prospective cohort studies. N Engl J Med 1999;340(13): 977-987. Doi: 10.1056/NEJM199904013401301

29 Mandelbrot L, Le Chenadec J, Berrebi A, et al. Perinatal HIV-1 transmission: interaction between zidovudine prophylaxis and mode of delivery in the French Perinatal Cohort. JAMA 1998;280 (01):55-60. Doi: 10.1001/jama.280.1.55

30 Boer K, England K, Godfried MH, Thorne C; European Collaborative Study. Mode of delivery in HIV-infected pregnant women and prevention of mother-to-child transmission: changing practices in Western Europe. HIV Med 2010;11(06):368-378. Doi: 10.1111/ j.1468-1293.2009.00800.x

31 Senise J, Bonafé S, Castelo A. The management of HIV-infected pregnant women. Curr Opin Obstet Gynecol 2012;24(06): 395-401. Doi: 10.1097/GCO.0b013e328359f11e

32 International Perinatal HIV Group. Duration of ruptured membranes and vertical transmission of HIV-1: a meta-analysis from 15 prospective cohort studies. AIDS 2001;15(03):357-368

33 Cotter AM, Brookfield KF, Duthely LM, Gonzalez Quintero VH, Potter JE, O'Sullivan MJ. Duration of membrane rupture and risk of perinatal transmission of HIV-1 in the era of combination antiretroviral therapy. Am J Obstet Gynecol 2012;207(06):482. e1-482.e5. Doi: 10.1016/j.ajog.2012.10.862

34 Peters H, Byrne L, De Ruiter A, et al. Duration of ruptured membranes and mother-to-child HIV transmission: a prospective population-based surveillance study. BJOG 2016;123(06): 975-981. Doi: 10.1111/1471-0528.13442

35 Menezes Succi RC. Mother-to-child transmission of HIV in Brazil during the years 2000 and 2001: results of a multi-centric study. Cad Saude Publica 2007;23(Suppl 3):S379-S389. Doi: 10.1590/ S0102-311×2007001500006 